Fecha de recepción: octubre 2019

Fecha de aceptación: diciembre 2019

Versión final: diciembre 2021

\section{El arte wixárika: un lenguaje visual para la defensa de su cultura}

Agustín Tonatihu Hernández Salazar ${ }^{1} y$ María Eugenia Pérez Cortés ${ }^{2}$

Resumen: El pueblo wixárica o huichol es una de las comunidades indígenas más antiguas de México, y se les asocia popularmente con diversos mitos, como el considerarlos los últimos guardianes de las auténticas tradiciones prehispánicas o el creerlos un pueblo de chamanes debido al uso ritual que hacen de un hongo alucinógeno al que denominan hikuri. A partir de las experiencias resultantes del uso de este alucinógeno y de su propia cosmogonía, los wixárika han desarrollado una estética psicodélica que se manifiesta en diversas expresiones artísticas muy apreciadas por su técnica, su complejidad, su belleza y el misticismo que parecen guardar. Este arte les ha permitido hacerse visibles en una nación que no acostumbra atender a sus pueblos originarios y ha sido también la firma que han presentado en sus luchas contra el despojo de sus tierras y de Wirikuta, un extenso territorio considerado uno de los sitios más sagrados para esta cultura, y que está en riesgo de desaparecer bajo intereses mineros. El propósito de este articulo es describir este estilo particular del arte wixárika y el valor que ha tenido como signo de identidad en la defensa de Wirikuta y de toda su cultura.

Palabras clave: Huicholes - Wirikuta - Arte wixárika - Indígenas mexicanos - Arte huichol.

[Resúmenes en inglés y portugués en las páginas 233-234]

(1) Mtra. María Eugenia Pérez Cortés: Maestra en Comunicación y Tecnología Educativa y Licenciada en Diseño de la Comunicación Gráfica, profesora de tiempo completo con 27 años de experiencia en la Lic. en Diseño para la Comunicación Gráfica en el CUAAD. Sus intereses profesionales giran alrededor del estudio de la tipografía y el uso de las Tecnologías de la Información y la Comunicación (TIC's) en la docencia. Mail: ma.eugenia. perez@academicos.udg.mx

${ }^{(2)}$ Mtro. Agustín Tonatihu Hernández Salazar: Maestro en Ciencias de la Educación y Licenciado en Diseño y Comunicación Gráfica, con 18 años de experiencia profesional y 14 años de experiencia docente en los campos del Diseño Gráfico y la Comunicación Visual. Actualmente estudia el doctorado en Metodología de la Enseñanza y se interesa en la investigación y difusión del conocimiento relacionados con el análisis y la producción de la imagen. Mail: tonatihu.hernandez@academicos.udg.mx 


\section{Introducción}

Wirikuta es un sitio ubicado en el estado mexicano de San Luis Potosí. Pero es mucho más que una ubicación geográfica, es uno de los cinco lugares sagrados más importantes de un pueblo indígena mexicano llamado Wixárica conocido frecuentemente como Huichol. El término wixárica significa "persona de corazón profundo que ama el conocimiento" (Chapela, 2006, p. 11).

Los indígenas Wixarikas cuentan con una cosmogonía milenaria que se ha heredado de generación en generación, son amantes de la naturaleza, del universo y de acuerdo a sus creencias en Wirikuta se llevó a cabo la creación del mundo.

Existen muchos sitios sagrados para el pueblo wixárika, sin embargo aparte de Wirikuta, los más representativos son otros 4 lugares de vital importancia, ubicados dentro de los estados mexicanos de Durango, Jalisco, Nayarit y Zacatecas.

a. WIRIKUTA es una localidad ubicada al oriente en los municipios Sierra de Catorce, Villa de la Paz, Matehuala, Charcas y Villa de Ramos en el estado de San Luis Potosí.

b. TATEI HARAMARA se encuentra al poniente, está representada por las dos piedras blancas -Tatei Waxieve y Tatei Yikawina-, que se encuentran frente al Puerto de San Blas en el estado de Nayarit. La cultura wixarika la conoce como la puerta sagrada de entrada al quinto mundo en donde el Sol se oculta para renacer día con día por Wirikuta.

c. XAPAWIYEME - XAPAWIYEMETA está ubicado en el estado de Jalisco, en la Isla de los Alacranes que ese encuentra dentro del Lago de Chapala.

d. HAUXAMANACA está ubicado en la parte alta de Cerro Gordo en el estado de Durango. e. TEE'KATA, ubicado en Santa Catarina Cuexcomatitlán, en el estado mexicano de Jalisco, conocido como el lugar del fuego primigenio, donde nació el Sol; se encuentra ubicado en el municipio de Mezquitic, Jalisco, el corazón del territorio wixárika.

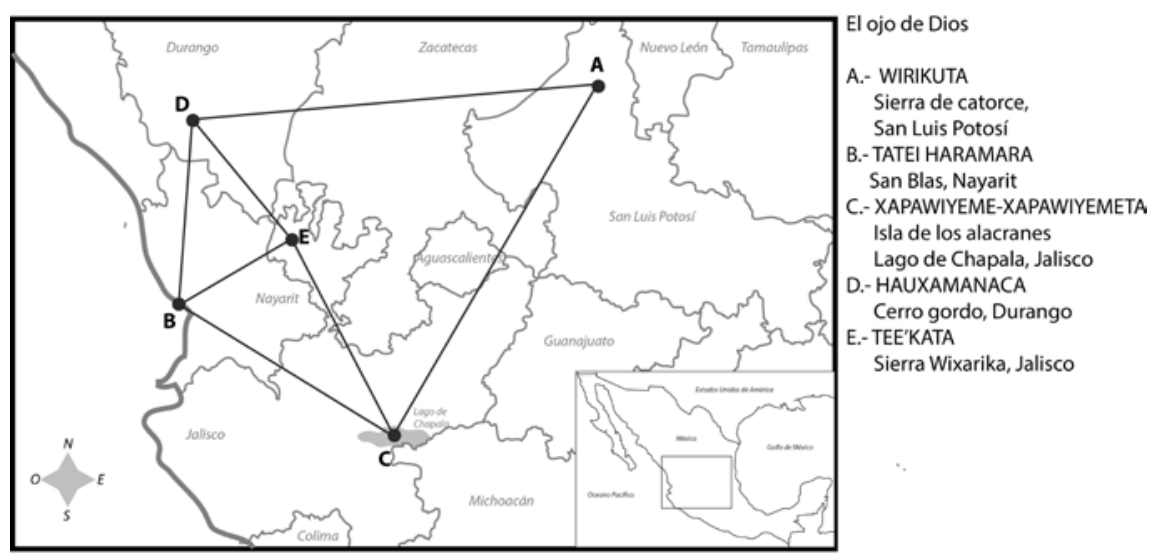

Figura 1. Mapa de ubicación de los cinco principales lugares sagrados de la cultura wixarika en el territorio mexicano. Elaboración propia a partir de Téllez (2014). 
Según Neurath (2003), "Estos cinco lugares, en su conjunto, forman una cruz romboide (ts+kuri), emblema cosmogónico por excelencia de los huicholes" (p. 23). Es de suma importancia señalar que los sitios sagrados cuentan con un significado muy especial, representan lugares en donde el Sol nace y muere diaramiente y forman parte de la identidad y la continuidad de su cultura.

\section{La cosmovisión del pueblo wixárika}

Siguiendo a López Austin (2016) entenderemos que la cosmovisión es:

Un hecho histórico de producción de procesos mentales inmerso en decursos de muy larga duración, cuyo resultado es un conjunto sistémico de coherencia relativa, constituido por una red de actos mentales, con la que una entidad social, en un momento histórico dado, pretende aprehender el universo en forma holista (p. 22).

De acuerdo con este mismo autor, los actos mentales son el producto de la interacción social y toda cosmovisión tiene un núcleo duro, constituido por la red colectiva de estos actos mentales, que cambia con extrema lentitud, y también tiene una periferia en donde, por el contrario, los actos mentales cambian muy rápidamente. En el caso del pueblo wixárika, éste es reconocido por haber mantenido casi intacta su concepción del universo, es decir, su núcleo duro cosmogónico, a lo largo de los distintos periodos históricos sucedidos en México a partir de la época de la Conquista, al tiempo que se adaptaba a las nuevas situaciones del entorno. Anguiano (2016) expone que la cosmovisión del pueblo wixárika,

Considera que el hombre debe de colaborar con las deidades para mantener el orden cósmico: la alternancia del día y la noche, así como la temporada de lluvias y de secas. En otras palabras, la vida sobre la Tierra. Ello se logra a base de ceremonias con complicados rituales; peregrinaciones y visitas a los lugares sagrados, llevando ofrendas muy variadas.

Dentro de la cultura wixárika los lugares sagrados son el pilar fundamental de su cosmovisión. Son sitios geográficos, lugares míticos, a los cuales deben acudir los huicholes y dejar sus ofrendas año con año. Los lugares sagrados son numerosísimos: cuevas, montañas, cerros, peñas o peñascos, picos, cañadas, barrancas, mesetas, el desierto, algunas piedras, manantiales, ojos de agua, fuentes de agua, lagunas, lagos, ríos, arroyos y el mar (p. 3).

En esta cosmovisión existen tres niveles en el mundo: el inframundo, a dónde van los muertos a purificarse, la superficie y el cielo; y cinco rumbos: los cuatro puntos cardinales y el centro -documentados en la Figura 1-. En ellos habitan los dioses, cuya función esencial, no fue crear el mundo y a los seres que lo habitan, sino ordenar el caos existente: 
Cuentan que hace muchos años, cuando la luz de la luna y las estrellas eran las únicas que iluminaban a nuestro planeta, los antepasados salieron del mar. Los dioses formaron el primer grupo de jicareros en busca de un venado y el cerro del Amanecer. Cuando llegaron al cerro, un venado se ofreció voluntariamente [para ser cazado] y su corazón se convirtió en peyote. Entonces, la luna entregó a su hijo, un niño ciego y cojo, pero muy buen cazador, quien al arrojarse al fuego y atravesar el inframundo resurgió como el Sol, nuestro padre Tayau. Fue así el nacimiento de la primera cacería y el primer amanecer. Así lo cuentan los wixárika (68 voces, 2016, s/p).

Además de esos dioses, el pueblo wixárika tiene muchos otros. Todos viven en la naturaleza y los wixaritari se comunican con ellos a través de ofrendas, cantos y danzas. Las deidades femeninas pertenecen a la temporada de lluvias y las masculinas a la temporada de secas, de modo que habitan en regiones distintas y están en eterno combate por prevalecer unas sobre las otras. El pueblo wixárika se encarga de mantener el equilibrio natural entre ambas fuerzas por medio de rituales y fiestas específicas celebradas a lo largo del año. Este mito fundador es representado cada año por grupos de wixaritari que peregrinan a la región de Wirikuta para realizar rituales y recoger peyote-conocido como hi ikuri, es una cactácea alucinógena, endémica de la zona y de pequeñas dimensiones que tiene un centro obscuro-, como parte de su obligación de mantener el equilibrio de la naturaleza. Esta peregrinación es conocida como nana'iyary que literalmente significa "el camino del corazón" y que de acuerdo a su tradición, fortalece su cultura y el corazón colectivo siendo descrita por diversos autores y destacando en ella el uso de una variada iconografía ritual. La peregrinación entra en el territorio sagrado de Wirikuta, en donde solo pueden entrar los que están puros, por lo que se hacen una serie de rituales de purificación en varios lugares.

La experiencia se transmite de generación en generación porque para ellos es indispensable vivirla y reproducirla cotidianamente para garantizar la continuidad del grupo. Durante estos trayectos, entre otras cosas, se llevan a cabo ritos de iniciación con la finalidad de que los adolescentes del grupo reconozcan y valoren su cultura. En términos generales, aunque existen relaciones consaguíneas entre los integrantes de la comunidad, también existen complejos sistemas de ceremonias, rituales, cargos, cantos y danzas que van fortaleciendo la cohesión del grupo y se van estableciendo lazos estrechos, especialmente con otros miembros del grupo que se reconocen como descendientes de un antepasado común. Estas peregrinaciones expresan mucho de la organización social que caracterizan a este pueblo. 


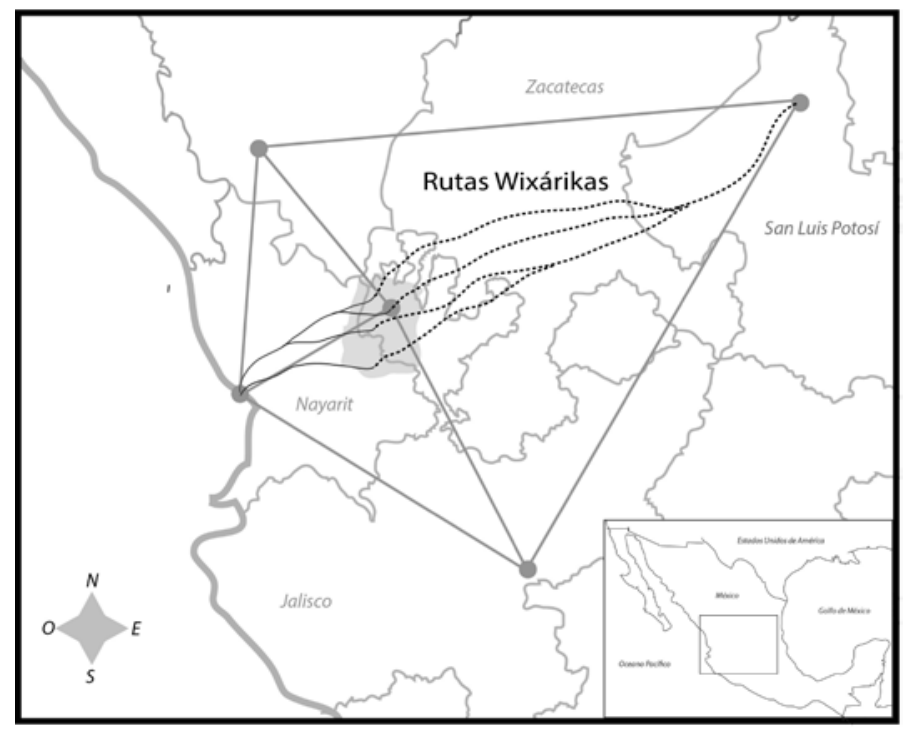

Figura 2. Rutas de peregrinación del pueblo Wixárica. En el centro puede apreciarse en gris claro, el principal asentamiento Wixárica en el país. Elaboración propia a partir de Sistema de Información Cultural, México, 2019.

\section{La iconografía de los wixaritari}

Siendo este grupo una cultura tan antigua, con poca influencia del cristianismo, su cosmovisión nos puede resultar muy compleja, no es de extrañar que en torno a ellos hayan surgido a su vez una capa de mitos y estereotipos que tratan de interpretarlos y vuelven muy atractiva su producción visual para los indigenistas, los turistas culturales, los estudiosos del arte e incluso para gente no interesada comúnmente en estos temas.

Los huicholes owixaritari -wixárika en singular-, son uno de los pueblos indígenas de México en torno a los cuales se han construido más estereotipos. Se ha dicho de ellos que son en su mayoría chamanes-artistas, que conservan costumbres prehispánicas, que son una suerte de eslabón perdido entre los antiguos pobladores de Mesoamérica y los grupos actuales y que son los mexicanos más "auténticos", entre otras afirmaciones que han contribuido a crear en torno a este pueblo una suerte de aura con la cual ellos han aprendido a moverse (Neurath, 2013, p. 15).

Ya a inicios del siglo XX, el noruego Carl Lumholtz había publicado, como producto de sus expediciones a México entre 1890 y 1998, una serie de investigaciones sobre los grupos indígenas que habitaban en el noroeste de México y que por aquel entonces eran desconocidos incluso para los habitantes mestizos de la región. Entre estos grupos indígenas se 
encontraban los wixaritari, con quienes convivió aproximadamente ocho meses. Como resultado de este trabajo Lumholtz publicó, entre otros textos, un informe muy detallado en que se centraba en la comunicación iconográfica de la etnia. El texto finalmente fue editado en español muchas décadas después, en 1986, por el Instituto Nacional Indigenista de México con el título de El arte simbólico y decorativo de los huicholes.

Para cuando surgió esta edición en México, los wixaritari se habían vuelto relevantes en los estudios etnográficos y de divulgación de las culturas indígenas, pero, en particular, su arte simbólico y decorativo había saltado a las galerías y museos a nivel internacional y se habían ganado el título de pueblo de artistas chamánicos. Y en efecto, al comparar los hallazgos documentados por Lumholtz hace más de cien años con el arte wixárika que puede apreciarse en la publicación Arte Huichol de la Revista Artes de México (2005), parece evidenciarse un cambio radical en la representación visual de la cosmovisión del grupo. Lumholtz dedica la mayor parte de su libro a describir los objetos ceremoniales wixárica, pero también presenta un catálogo muy amplio de símbolos utilizados en la decoración de objetos de uso cotidiano. Entre los muchos objetos artesanales que el pueblo wixárika elabora con fines rituales se encuentran los siguientes:

- Nierika. Son discos de piedra con un orificio en el centro a través del cual los ancestros pueden observar las ofrendas que les han colocado o cómo se están desarrollando los rituales. Se colocan en la entrada de los adoratorios y están adornados con iconografía en ambas caras, dedicada a alguno de los múltiples dioses el panteón wixárika.

- Xukúri. Es una vasija semiesférica conocida como jícara, hecha de huaje -una fruta similar a una calabaza-, o de barro. Su interior aparece decorado con figuras humanas, plantas o animales formadas por cuentas de chaquira, semillas de maíz, piedras u otros objetos. Los íconos representan plegarias dirigidas a los ancestros, de manera que las jícaras rituales son canales de comunicación hacia los dioses. En las peregrinaciones a Wirikuta, los jicareros son los hombres encargados de las jícaras y a través de ellas se convierten en los representantes de los primeros hombres, que salieron del mar y fueron a la caza del venado.

- trit. Es una flecha de madera o carrizo por medio de la cuál se hacen peticiones a los dioses clavándolas en la tierra o en algún adoratorio. Para algunos autores, la petición y el dios al que se dirige se codifican por medio de los adornos que se agregan a la flecha. Las decoraciones son muy variadas e incluyen iconografía pintada o diversos aditamentos, como plumas, bordados, lazos, escudos e incluso objetos más elaborados, como sandalias o pequeños bancos. La persona-flecha incluye un trozo de cuarzo, que representa el alma cristalizada de un antepasado muerto o de un anciano cercano al grupo familiar.

- Tsikiri. Es una cruz formada por dos varitas entretejidas con estambre para formar entre uno o varios rombos de distintos colores. Se conoce popularmente como ojo de dios. Los colores varían de acuerdo con la deidad a la que se dedican. El ojo permite a los wixaritari ver y entender cosas desconocidas, a la vez que permite a los dioses observar a los seres humanos. En la fiesta del tambor, los niños son presentados a los dioses mediante los tsikiri (Ver Figura $3^{1}$ ).

- Muwiéri (Ver Figura $3^{2}$ ). Es una vara ceremonial cubierta de estambre de colores con dos plumas en la punta que apuntan hacia arriba, además de otras dos que cuelgan libre- 
mente. Le permite al mara'akáme comunicarse con las deidades, los lugares sagrados y los rumbos cardinales. También le ayuda a curar a los enfermos. De acuerdo a Torres (2016), “el mara’akáme es el sujeto formado para internarse en la esfera de lo sagrado, maniobrar las fuerzas disponibles y obtener frutos benéficos para sí y la comunidad” (p. 57).

- Itari. Es un objeto tejido que sirve como cama o esterilla y se ofrece como ofrenda a los dioses. Se elabora de diversos materiales como varitas, estambre, lana o algodón y se adorna con símbolos sencillos.
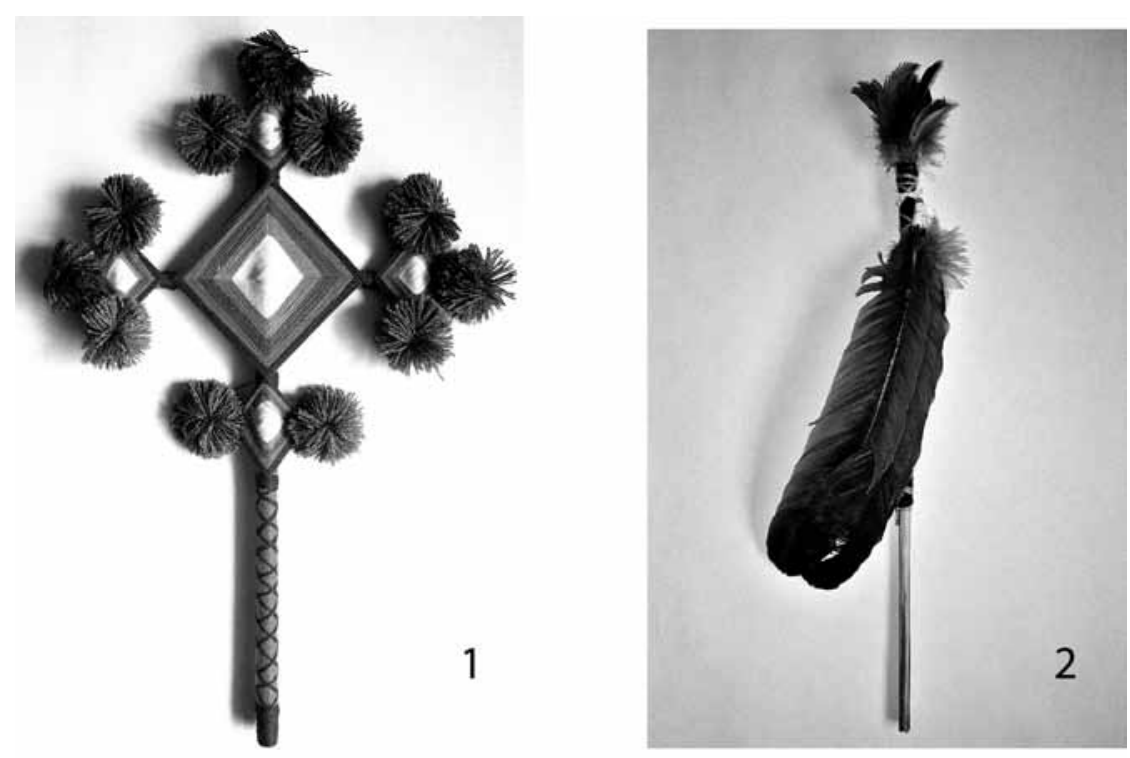

Figura 3. Tsikiri u Ojo de $\operatorname{Dios}^{1}$ y Muwiérit realizados para su venta a turistas. Colección propia.

Entre los objetos de uso cotidiano se encuentran los cuencos para transportar agua, eslabones para encender fuego, morrales, fajas y la indumentaria de hombres y mujeres. Tanto para la simbolización de los objetos sagrados como para la decoración de los objetos de uso cotidiano, el pueblo wixárika cuenta con un gran repertorio de imágenes que se reinterpretan al gusto del artesano. Lumholtz presenta, por ejemplo, una amplia cantidad de motivos geométricos que aparecen dispuestos en grecas en textiles y objetos diversos. De la naturaleza igualmente se pueden observar representaciones de diversas flores, frutos, plantas y, por supuesto, el peyote. Además, se aprecian una larga lista de animales, destacando el venado entre los tigres, pumas, perros, ardillas, caballos, toros, águilas, serpientes, 
pavos, urracas, colibríes, ranas, cangrejos, camarones, alacranes, mariposas, ciempiés, saltamontes y otros más. En los objetos rituales, estos motivos, pintados o bordados, suelen aparecer aislados y en los objetos cotidianos, formando patrones de repetición.

Para Mata (1972), los motivos que adornan los objetos de uso cotidiano y particularmente la indumentaria, son decorativos y no tienen sentido ritual:

Aunque varios componentes de los adornos son estilizaciones del venado (encarnación de la bondad), del águila (sostén del mundo), y de la serpiente (representación de la lluvia, del rayo o del movimiento), o elementos mágicos, como las flores, que son solicitudes de lluvia y de vida, los bules que simbolizan el agua, los eslabones que representan al Dios del Fuego o las líneas quebradas, que reproducen el relámpago, no podemos asegurar que rigurosamente todos, absolutamente todos los adornos y las figuras de los bordados y de los tejidos tengan un sentido mágico o religioso, que estén puestos para algo (p. 45).

En la Figura 4 se puede apreciar el detalle de los bordados wixaritari en algunas piezas de un traje de hombre. El traje de hombre está compuesto por sombrero, calzón largo -huerruri-, camisa larga con los costados abiertos -kamirra o kutami-, una capa corta que va sobre los hombros -tubarra-, faja ancha para ceñir la cintura -juayame o kuyame- y una especie de carrillera hecha con morralitos decorativos que se sujeta a la faja-uihuame o huaikuri-. Además, como el traje no tiene bolsas, los wixaritari usan uno o varios morrales profusamente bordados. Todas las piezas se bordan a juego, con diversos símbolos, para producir un conjunto armónico.
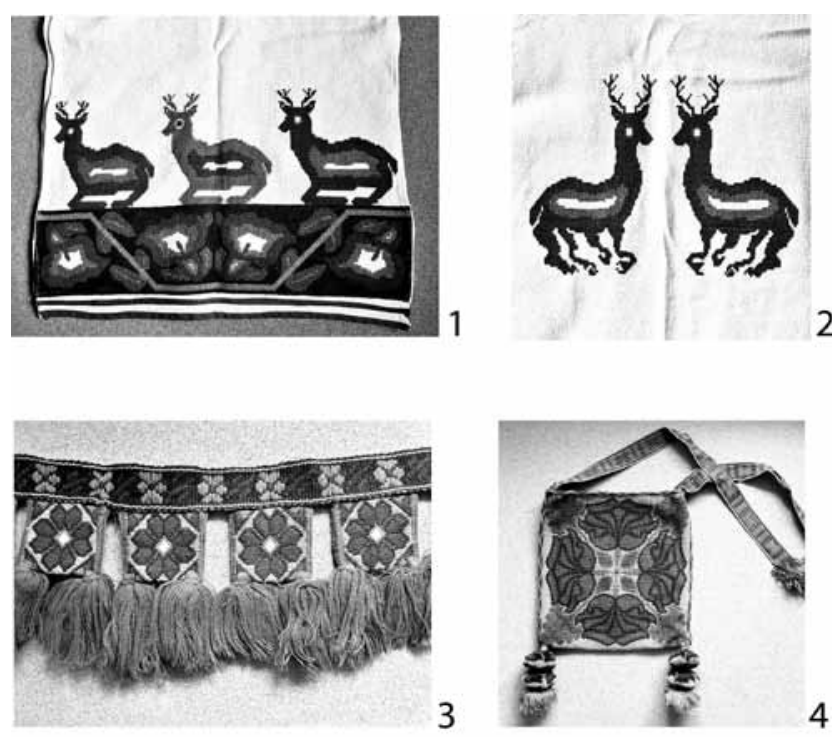

Figura 4. Detalle del bordado de venados y flores en la parte inferior de una kamirra ${ }^{1}$, detalle del bordado de venados en el pecho de la kamirra ${ }^{2}$, detalle del bordado de flores y peyotes en la kuihuame del mismo traje $\mathrm{e}^{3}$, bordado de flores en el morral del mismo traje $\mathrm{e}^{4}$. Colección propia. 
En el arte moderno wixárika, aunque prevalecen los objetos ceremoniales, los símbolos y materiales, es notaria la introducción de nuevas técnicas de expresión y en particular la aparición de un estilo de representación que puede considerarse psicodélico o chamánico. Estos nuevos objetos, tan atractivos por su colorido como por su estética, en su mayor parte son cuadros de estambre, objetos cubiertos con chaquira, indumentaria y muñecos auto-representativos. De ellos hablaremos con más detalle en el siguiente apartado.

Antes, cabe señalar que este arte moderno del pueblo wixárika es el que más ha llamado la atención de las personas ajenas al grupo étnico. Además del valor artístico intrínseco en estas obras, como ya se mencionó más arriba, al grupo se le suelen atribuir estereotipos relacionados con lo puro, lo mágico y lo chamánico. Adicionalmente, su campaña de defensa del territorio sagrado de Wirikuta los ha puesto en el ojo de la opinión pública y ha incentivado estas ideas. Negrín da Silva advierte que diversas empresas han aprovechado este contexto para, cuando menos, cosificar la cultura wixárika y convertirla en un producto más del mercado de masas:

En algunos casos, son empresas privadas incipientes que proclaman un compromiso social, aunque a menudo indeterminado, con el pueblo wixárika; otras empresas simplemente utilizan la estética huichol por su belleza barroca sin declarar algún compromiso filantrópico.

Sin duda la reciente explosión en el mercado de productos 'huicholes' es parte de un proceso global capitalista que depende de la creciente importancia social, política y ambiental de las identidades étnicas. [...] los nuevos horizontes capitalistas encuentran oportunidades en el diseño de productos que enfatizan conexiones sociales y compromisos filantrópicos, a menudo con pueblos que se imaginan como 'otros' por encontrarse distantes en el tiempo y en el espacio (Negrín, 2015, p. 56).

\section{Origen y razón del arte moderno wixárika}

Debido a que los wixaritari no habitan en los sitios en donde, de acuerdo con su cosmovisión, ocurrieron los hechos narrados en sus mitos y se organizó el mundo tal como lo conocemos, son un pueblo de peregrinos. De acuerdo con el historiador Fernando Benítez (Benítez, en Lumholtz, 1985) a través de las peregrinaciones los wixaritari reconstruyen las hazañas creadoras de sus dioses justo en dónde estás ocurrieron. Esas hazañas, los mitos fundadores, no están escritos, sino que son cantados por los iniciados en los rituales del grupo.

Anguiano (2016) explica que la efervescencia por el arte wixárika inició en la década de 1950, cuando se montó en la Ciudad de México una exposición de artesanías wixaritari recolectadas in situ. Impresionado por la exhibición, el entonces gobernador de Jalisco, estado donde en parte habita este grupo étnico, ordenó que se llevarán a la región donde habita el grupo materiales para que los wixaritari realizarán más artesanías con el propósito específico de exhibirlas al público citadino en lugar de destinarlas a ser ofrendas. Con 
los cuadros resultantes, hechos de lana, se montó una segunda exposición en la ciudad de Guadalajara, México, donde fueron muy apreciadas y se generó un mercado para el arte de cuadros de estambre de colores wixárika que fue fomentado por antropólogos, compradores de arte y hasta por sacerdotes franciscanos.

En un principio, sigue Anguiano (2016), los cuadros de estambre, en que representaban su cosmovisión, ceremonias y mitos eran obras coloridas, pero de estilo esquemático, con grandes fondos sin motivos y centradas en un sólo símbolo. En 1965 el antropólogo Peter Furst le pidió al mara'akáme -figura equivalente a un chamán para la gente ajena la grupo-, Ramón Medina para entonces un muy reconocido artista wixárika, que realizara cuadros con narrativas y mitos para la colección del Museo de Artes Étnicas de la Universidad de California.

[...] el antropólogo Peter Furst contrató al aprendiz Ramón Medina quien, como todos los huicholes, sabía hacer ofrendas de estambre pegado con cera a una tabla. Medina cantó sus mitos y a Furst se le ocurrió la idea de que los describiera al modo de sus ofrendas.

Esto ha determinado una falsificación y una industria. Medina, por ejemplo, "pintó" el camino de los muertos y a lo largo del inframundo -el mismo de Sahagún con variantes locales-, pero como no se pintaba a los muertos los imaginó como flotantes cabezas encapuchadas al estilo de los fantasmas de Walt Disney.

Era capaz de describir todos los mitos con un gran sentido plástico, pero eran tablas que tenían poco en común con las antiguas ofrendas. Creo que este género podría llamarse un nuevo arte huichol y tuvo numerosos imitadores. Ahora se cree que es el arte auténtico de los huicholes y en realidad son hermosos y decorativos y relatan fragmentos de sus mitos [...] (Fernando Benítez, en Lumholtz, 1985, p. 7)

En la década de los '60, enseñados por Ramón Medina y por su esposa, Guadalupe de la Cruz, surgieron otros grandes artistas wixaritari. Entre ellos Eligio Carrillo, Fabián González, Domingo González, José Isabel González y José Benítez. El nuevo arte wixárika se volvió colorido, con diseños que se pueden describir como psicodélicos, producto del consumo del hongo alucinógeno conocido como peyote. Además, las temáticas dejaron de ser simples y los artistas comenzaron a realizar elaboradas narrativas visuales de sus mitos, creencias y rituales, cubriendo todo el espacio del cuadro con iconografía para producir así un estilo muy propio, que sin ser rigurosos podría describirse como barroco psicodélico.

De acuerdo con Iturrioz

Las tablas de estambre se desarrollan en la actualidad a partir principalmente del objeto ritual llamado nierika, que sirve de significante a una red compleja de representaciones simbólicas dentro del discurso y de las prácticas religiosas tradicionales. El precedente histórico de estas tablas son por tanto las sencillas tablitas que describía Lumholtz a principios del siglo XX, sobre las cuales se 
pegan perlitas de chaquira y estambres de colores con cera de abeja. [...] La palabra nierika significa "ver", "estar despierto", estar vivo", "estar consciente" (Pacheco e Iturrioz, 2003, p. 40).

Para Pacheco (Pacheco e Iturrioz, 2003), los cuadros de estambre del arte moderno wixárika escapan a la comunicación entre la comunidad y sus dioses para volverse transmisores universales de las representaciones y costumbres simbólicas de la etnia.

Un nierika es un espejo en que se reflejan aspectos de su cultura material y sobre todo, religiosa, una ventana que nos permite asomarnos a otra realidad y a los procesos en que los huicholes la construyen, generando así su propia identidad colectiva. El nierika se ha convertido así en una herramienta de comunicación intercultural (p. 46).

El arte de los cuadros de estambre puede apreciarse ahora a escala mural en dos obras del mara'akáme José Benítez Sánchez. La primera se encuentra en el Museo Nacional de Antropología de la Ciudad de México y se titula La visión trascendental de Tatutsi Xuweri Timaiweme. El cuadro pintado con estambre mide 244 x 122 centímetros y fue elaborado en 1980.

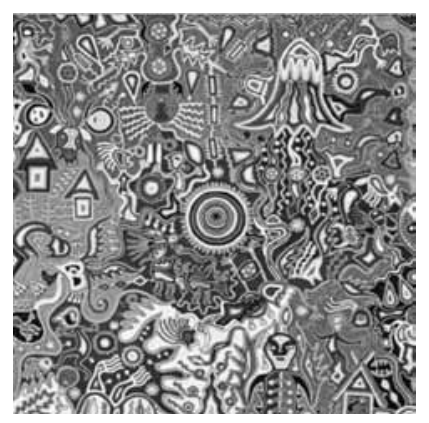

Figura 5. La visión trascendental de Tatutsi Xuweri Timaiweme. INAH (s/f.).

En el pueden reconocerse muchos de los símbolos de la religiosidad wixárika y la complejidad de su cosmovisión:

La visión de Tatutsi Xuweri Timaiwemees una de las más importantes obras artísticas de esencia ritual de la cultura wixarika o huichol.

Además de su gran calidad de manufactura, belleza, personalidad estilística y fascinante uso del color, encierra un inmenso valor como fuente etnográfica de primera mano para ahondar en la cosmovisión de los huicholes.

En ella se pueden encontrar referencias a al menos 13 deidades, 9 de sus mitos cosmogónicos y 9 de sus símbolos más representativos. La compleja y a veces paradójica relación de sus elementos y sus diversos estratos de lectura reflejan fielmente la riqueza y dinamismo de la cultura wixarika. 
A primera vista la saturación de elementos y personajes es abrumadora; pero una mirada sin prisa permite que se vayan revelando y desdoblando los significados. La imagen devela un enorme rostro, al tiempo que es un retrato del numeroso panteón huichol. Es una visión sagrada, una revelación de peyote. Pero es también un mapa de los muchos sitios sagrados del territorio huichol. Es además un rico referente de sus más representativos episodios mitológicos, un mosaico de historias que encierran su sabiduría ancestral y mágica. Como en la mayoría de los mitos huicholes, distintas versiones ayudan a comprender o reflejar un aspecto particular de la cosmovisión. Por eso la ambivalencia de varios personajes hace que encajen en ellos diversos matices del mismo relato. En descubrir esa riqueza reside la clave para observar esta obra.

Su lectura se vuelve infinita. Por eso la obra pide una contemplación pausada y, al mismo tiempo, ser revisitada una y otra vez para regalar siempre una visión rica y dinámica del mundo. Como la de los huicholes (INAH, s.f.).

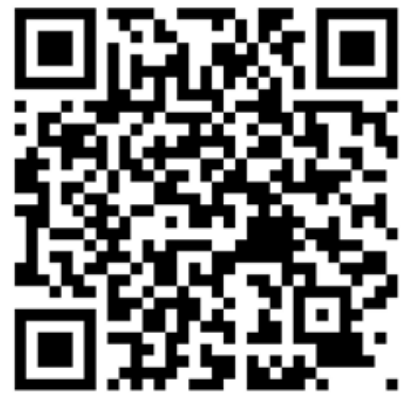

Figura 6. La visión de Tatusi Xuweri Timaiweme, elaborado por José Benito Sánchez en 1980. (Acceda al sitio oficial del Museo Nacional de Antropología, del Instituto Nacional de Antropología e Historia. México, escaneando el código QR).

El segundo cuadro mural de estambre al que se ha hecho referencia se encuentra en la Estación Benito Juárez del Tren Eléctrico Urbano de la ciudad de Guadalajara, México. Se titula La semilla del mundo y es una obra integrada por 20 paneles que se unen para formar el gran mural de 600 x 540 centímetros. En entrevista realizada por Ibarra y Carrillo (2005), el mara’akáme José Benítez explicó que "el mural cuenta el inicio del universo, detalla como fue creada la semilla del cosmos. Fue un 'sueño de los dioses para nosotros, para que podamos conocer primer mundo, segundo mundo y tercer mundo'” (p. 24). En la cosmovisión wixárika, nosotros existimos en el segundo mundo, que es el estómago ya que la tierra es un cuerpo dividido en tres partes. De la cintura para abajo se encuentra el primer mundo, que es el inframundo, y del cuello para arriba existe el tercer mundo, el cielo. Así, el cuerpo del ser humano es la encarnación del mundo mismo. En esta cos- 
movisión, los dioses vinieron al segundo mundo para traer la semilla y se la entregaron al primer hombre, llamado Watácame, para que la sembrara. De ella brotó todo lo que es sagrado para los dioses quienes se quedaron a vivir en el desierto de Wirikuta:

De acuerdo con Benítez Sánchez, los huicholes peregrinan cada año a Wirikuta para hallar a los dioses que moran en aquellas tierras, empresa que no resulta fácil, ya que sólo pueden hablar con ellos por medio de Kayaumari:

"Kayaumari es un venado que se convierte en maíz, águila, peyote... se convierte en varias formas. Es el interprete de los dioses. Sabe dónde están. Como yo. Mara'acame, conozco la palabra de los dioses, pero yo directamente no los veo. "Yo no estoy escuchando a los dioses, sino que Kayaumari trae la voz y me la entrega a mí. Yo la interpreto, yo la canto, hablo qué es lo que dicen los dioses. ¿Por qué? Porque Kayaumari está enfrente. Todo lo que dicen los dioses él lo sabe bien" (Idem).

Entrevistado por Gabriel Pacheco, el mara’akáme José Benítez describió la función ritual del peyote como medio para contactar con los dioses:

En Wirikuta comía peyote. Por la tarde, en el momento álgido de la ceremonia, todos los peregrinos comían. Por la noche sentía cosas raras: "todo lo que sentía, lo que veía, lo que llegaba a hacerme Nuestra Madre Hikuri [el peyote]. Y cada que ella me encontraba me sentía portando un morral. Dentro de mí sentía que algo parecido a una víbora fría se internaba en mí, recorría mi cuerpo de abajo hacia arriba hasta llegar a mi cabeza. Mientras tanto a Nuestro Hermano mayor (que es el peyote) [sic. El hermano mayor es el dios venado] lo oía silbar hasta que llegaba a mí, justo cuando estaba bajo los efectos del peyote. Esto me sucedía allá en el lugar del peyote cuando yo intentaba asimilar lo que veía y sentía con él. Al regreso a casa los peyoteros teníamos que dar inicio a la caza del venado. Durante la noche los lloridos del venado me llevaban a encontrarme con el verdadero anunciado en el canto" (Pacheco e Iturrioz, 2003, p. 40).

Neurath (2013) sostiene que inicialmente los wixaritari comerciaron principalmente con las tablas de estambre, inspiradas en los efectos del peyote. Las tablas suelen incluir al reverso una explicación de la simbología expuesta al frente, de manera que el comprador puede acceder a parte de la mística que se atribuye a los wixaritari. Posteriormente, son los objetos de cubiertos de chaquira los que se han vuelto muy populares entre los turistas y personas interesadas en el indigenismo. Por ejemplo, en los sitios especializados en la venta de arte wixárika, se pueden encontrar, además de los morrales tejidos y los cuadros de estambre, diversos objetos cubiertos con chaquiras de colores: pequeños huevos, jícaras, toda clase de figuras de animales, calaveras, «eclipses» de sol y luna y pequeñas cajas decoradas. También hay disponibles accesorios como aretes, broches, collares, pulseras y pectorales. Todos con el estilo artístico wixárika. 
Además, en sitios no especializados, como Amazon o Mercado Libre México se pueden encontrar desde los más tradicionales objetos cubiertos con chaquira hasta otros de supuesta manufactura wixárika que escapan a los que comúnmente comercia la etnia como, por ejemplo, llaveros, zapatos, gorras, cráneos de toro, balones de futbol americano y hasta latas de refresco. Incluso, con la técnica de «pintar con chaquira», en 2010 ocho artesanos wixaritari cubrieron con más de dos millones de estas cuentas de colores un Volkswagen Sedán. El automóvil intervenido, llamado Vochol, tenía como propósito difundir el pensamiento y la filosofía wixárika, de acuerdo con el Consejo Nacional para la cultura y las Artes de México.

Le Mûr (2015) afirma que este uso comercial de la artesanía Wixárika como medio para representarlos ha sido uno de los ejes de las políticas indigenistas del gobierno desde la década de 1970:

Se encontraba en ello una oportunidad de desarrollar el sector turístico, ya floreciente, y a la vez, un método rentable para integrar a los pueblos indígenas a la sociedad mayoritaria. El programa gubernamental Huicot implementó políticas indigenistas masivas y afectó profundamente las comunidades wixáritari de Jalisco y Nayarit. La comercialización de la artesanía y el folclor huichol fue uno de los mayores objetivos de este programa, e influyó mucho para que la venta de artesanía se transformara en una de las estrategias de supervivencia más importante de los huicholes (p. 115).

Para Neurath, un objeto particularmente definitorio del arte moderno wixárika es la máscara cubierta de chaquira, ya que es completamente opuesta a la máscara utilizada por el grupo étnico en sus rituales. La máscara ritual wixárika es monstruosa y su propósito es simbrar a aquel que observe al enmascarado, quien personifica a alguno de los dioses y encarna su poder.

Las máscaras rituales más importantes son objetos sumamente "delicados" y su uso está normado por una serie de tabúes. Cuando coleccioné las piezas para la sala del Gran Nayar del Museo Nacional de Antropología fue casi imposible lograr que los coras me fabricaran una copia de la máscara del Viejo de la danza de los Urraqueros (be'eme), mientras que con los huicholes tuve que abandonar el plan de conseguir los objetos equivalentes, las máscaras del bufón ritual tsikuaki y de la diosa Takutsi Nakawe. Estos objetos se guardan en cuevas sagradas y sólo se sacan para las fiestas que les correspondan. Quien fabrica una máscara nueva se compromete a custodiarla a veces por el resto de su vida; también se tiene que someter a prolongados ayunos para purificarse y protegerse de la fuerza potencialmente dañina del objeto, pues la máscara sanciona con enfermedades graves cualquier uso inapropiado (Neurath, 2013, p. 106). 


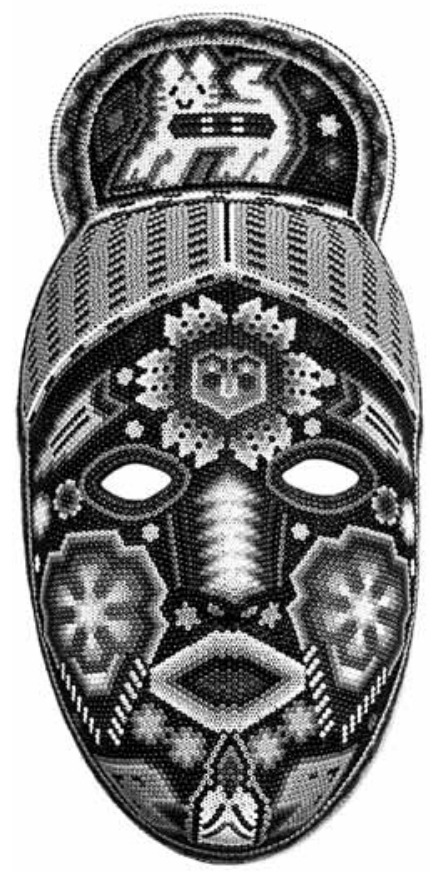

Figura 7. Máscara wixárika elaborada en papel recubierto de chaquiras por el artesano Higinio Hernández Carrilo, de venta en el sitio Amazon México. Amazon (2019).

Las máscaras que comercian los wixaritari (Ver Figura 7), por el contrario, carecen de ese poder ritual. Son en cambio reproducciones del estereotipo que los compradores no wixaritari, los vecinos, tienen de la etnia. Estas máscaras, como otros de los objetos cubiertos de chaquira ya mencionados, se basan en objetos rituales utilizados por el grupo, e incluso se elaboran utilizando los símbolos característicos de su cultura, pero se han desacralizado ya que la decoración no tiene significados rituales y la composición simbólica no pretende representar a ningún personaje, sino simplemente decorar el objeto de manera que el comprador pueda reconocer los símbolos y darles una explicación mística. Con la máscara, el vecino puede personificarse como wixárika, pero no participa en absoluto de su religiosidad.

Da la impresión de que los huicholes se han percatado de lo que implica ser "el otro del otro" y, de cierta manera, en las máscaras artesanales se ven a sí mismos desde la perspectiva de nosotros, los no indígenas. De aquí puede deducirse que en la venta de estas máscaras ellos encuentran un contexto idóneo para controlar el manejo de su imagen en el exterior de sus comunidades. Además, la producción y venta de máscaras enmascaradas evita los problemas que suscita la producción de arte ritual. Podemos decir que este tipo de artesanía forma 
parte de una estrategia exitosa de participación en el mercado donde los objetos comercializados cumplen con la función de un guardián. Mientras que, en apariencia, se satisface la demanda por una espiritualidad indígena y se revela un conocimiento chamánico ancestral, se evita que el artista y el espectador se ofrezcan a la depredación ejercida por los otros. Asimismo, se impide la mediatización y transformación en mercancía de ciertos ámbitos de la vida ritual tradicional que no se consideran aptos para no iniciados (Neurath, 2013, p. 108).

Lo mismo que se deduce del comercio de las máscaras por parte de los wixaritari, puede pensarse de las auto/representaciones que hacen de ellos mismos en muñecos -masculinos y femeninos-, ataviados con su traje típico bordado con múltiples símbolos de su etnia y comúnmente portando en una mano un Ojo de dios (Ver Figura $3^{1}$ ) y en la otra un Muwiéri (Ver Figura $3^{2}$ ). A través de estas figuras los wixaritari también comparten parte de su ser indígena idealizado por los no indígenas y dejan entrever parte de su cosmovisión, pero al mismo tiempo protegen su rica vida ritual.

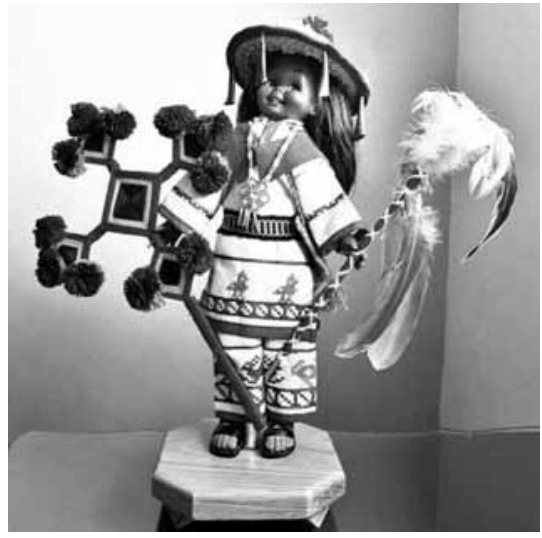

Figura 8. Auto/ representación wixárika a través de un muñeco artesanal. Colección propia.

Es evidente entonces que el pueblo wixárika ha encontrado nuevos tipos de expresión artística que son específicamente hechos para consumo externo. Esta comunicación simbólica les permite dar a conocer parte de su cosmovisión de una manera que puede considerarse incluso didáctica, al tiempo que trata de proteger su esencia de los embates de la cultura dominante en su entorno. El arte moderno huichol es un espejo que refleja con gran belleza la capa exterior del grupo, los estereotipos que hemos construido en torno a ellos, pero que protege su corazón, su núcleo duro, volviéndolo inaccesible para los no iniciados. 
Y es interesante apuntar que este modelo de comunicación que dice al tiempo que oculta surgió en parte a causa de los propios intentos de los estudiosos por conocer y comprender el núcleo de la cosmovisión wixárika. El intento de Furst por registrar los cantos de los mitos fundadores del grupo por medio de las ofrendas rituales llevo a los artistas wixaritari a desarrollar su peculiar estilo de contar los relatos, profuso en signos e impresionante en su ejecución y estética, pero reticente en la esencia ritual.

El arte moderno wixárika, que luego sería fomentado por el gobierno como parte de sus programas indigenistas y turísticos, muestra la imagen que el mundo occidental se ha construido de la etnia, pero oculta su cosmovisión. Es un caso en que la imagen visual de la entidad social se ha construido con la intención de complacer a los ajenos y no para intentar auto-representarse. Así, la imagen que los wixárika tienen de sí mismos permanece codificada en sus discretos usos y costumbres ancestrales, oculta en sus sitios sagrados, y es protegida del exterior por esa identidad moderna y adaptable que podría equipararse a una marca turística.

\section{La batalla por Wirikuta}

Por todo lo anterior, el pueblo Wixárika y su cultura, es considerado parte del legado cultural de México, por lo que se estima de vital importancia apoyar la protección de esta identidad, con todo lo que esto implica. Wirikuta forma parte de la Red Mundial de Sitios Sagrados Naturales de la UNESCO, desde 1998, es un área natural protegida con una extensión de 140 211,85 hectáreas y el 7 de octubre del 2000 se denominó Sitio Sagrado Natural de Wirikuta y la Ruta Histórico Cultural del Pueblo Wixárica.

De acuerdo a la Comisión Nacional para el Desarrollo de los Pueblos Indígenas (2010), México se ha adscrito a diversos acuerdos, decretos y planes de apoyo, de los cuales se destacan los siguientes:

En junio de 1992, México se suscribió al Convenio sobre la Diversidad Biológica, que promueve la Organización de las Naciones Unidas, el cuál es un tratado internacional que tiene como objetivo general promover medidas que conduzcan a un futuro sostenible y que en su primer artículo expone entre otras cosas, el trabajo a favor de la diversidad biológica y la participación justa y equitativa en los beneficios que se deriven de los recursos genéticos. Este mismo instrumento, en el inciso J del artículo octavo promueve el respeto y el apoyo para que las comunidades indígenas logren la utilización sostenible de la diversidad biológica y gozar de los beneficios derivados de la utilización de sus conocimientos (Comisión Nacional para el Desarrollo de los Pueblos Indígenas, 2010, p. 17).

La Organización Internacional del Trabajo en su convenio 169 sobre Pueblos Indígenas y Tribales en Países Independientes y que fue ratificado en México en el año de 1990, la cual establece que los pueblos indígenas tienen derecho a conservar todas o algunas de 
sus propias instituciones económicas, culturales, sociales y políticas, además de establecer que el Estado mexicano los consulte acerca de las medidas que planea tomar para proteger y preservar su medio ambiente además de toda aquella actividad que les pueda afectar directamente. Entre otras cosas el Estado también se compromete a reconocer el derecho a la propiedad de sus territorios además de respetar la importancia de la relación de los mismos con los habitantes que lo usan.

En 1981 México reconoce el derecho de los pueblos para disponer libremente de sus recursos naturales y riquezas, al ratificar el Pacto Internacional de Derechos Civiles y Políticos. A nivel nacional la Cámara de Diputados (2012) por conducto de la Constitución Política de los Estados Unidos Mexicanos en su artículo segundo, en su párrafo tercero, reconoce las comunidades de los integrantes de un pueblo indígena a "aquellas que forman una unidad social, económica y cultural, asentadas en un territorio y que reconocen autoridades propias de acuerdo con sus usos y costumbres" (de Diputados, C., 2012, p. 2). Así como reconoce en su inciso A, en los apartados I, IV y V su derecho a decidir las formas internas tanto de convivencia, como de organización social, económica, política y cultural; su derecho a preservar su lengua y todos aquellos elementos y conocimientos que constituyan su cultura y su identidad, así como conservar y mejorar el hábitat preservando su hábitat. Siendo el Presidente de la república, el Lic. Felipe Calderón Hinojosa, junto con los gobernadores de los Estados de Durango, Jalisco, Nayarit y Zacatecas, el 22 de abril del 2008, se firmó el Pacto de Hauxa Manaka para la preservación y desarrollo de la cutura wixarika, en donde las autoridades se comprometireon a realizar las acciones necesarias para preservar y mantener la continuidad histórica de la cultura y la identidad wixárica, junto con todos los elementos relacionados. A nivel regional, el estado mexicano de San Luis Potosí (1996) por conducto de la Constitución Política del Estado Libre y Soberano de San Luis Potosí, en su artículo noveno, entre otras cosas, declara que el reconoce la presencia regular de varios pueblos indígenas incluidos los Wirrarika o Huicholes, además de contemplar en los diez y seis apartados de este mismo artículo, los compromisos que adquiere para la seguridad y respeto de este sector de la población, su cultura, territorio, necesidades y costumbres. El mismo estado de San Luis Potosí, el 27 de octubre del año 2000 declara Área Natural Protegida Sitio Sagrado Natural de Wirikuta y la Ruta Histórico Cultural del Pueblo Wixárika. La conservación de esta área protegida es de vital importancia porque además de las cuestiones culturales, la vegetación de ésta área es esencial para el mantenimiento del ciclo ecológico, la conservación y propagación de cactáceas endémicas y en peligro de extinción, así como el registro de numerosas especies, entre las que se encuentran 19 de flora y 16 de fauna listadas en la Norma Oficial NOM-059 (Semarnat, 2010), la cual tiene por objeto identificar las especies en riesgo en el territorio nacional.

Sin embargo, a pesar de todos los esfuerzos anteriormente descritos, México está dividido, por un lado se han invertido muchos esfuerzos tanto públicos como privados para proteger estos espacios llenos de cultura e identidad, pero por otro lado, los sitios sagrados se encuentran muy vulnerables, ya que existen diversos factores que los amenazan constantemente, como por ejemplo los problemas diversos relacionados con la tenencia de la tierra, el turismo insensible, la contaminación, la extracción ilegal y uso comercial del híkuri-peyote-. 
Una de las amenazas más impactantes y dañinas es el otorgamiento en noviembre del 2009 por parte del estado mexicano de concesiones para la explotación minera del territorio Wirikuta, que abarcan una gran cantidad del área natural protegida, poniendo en alto riesgo la flora, fauna, mantos acuíferos y especies en peligro de extinción, erosionando gravemente el ecosistema y la identidad del pueblo wixarika.

\section{Conclusiones}

Una vez más, los intereses económicos rebasan las expectativas culturales, la identidad y la conservación del ecosistema. Y dado que los wixaritari manifiestan su cultura primordialmente por medio de cantos y ofrendas de fabricación artesanal ricas en iconografía, es en su expresión visual donde perdura y se puede apreciar de mejor manera tanto el núcleo de su cosmovisión como su capacidad de adaptarse a cada tiempo para conservar intacto ese núcleo.

En medio de constantes conflictos por la defensa de la tierra, sus sitios sagrados y su identidad cultural, el pueblo wixárika ha sabido conservar su espiritualidad embotando por medio del arte visual los sentidos de quienes pretenden llegar al conocimiento que ellos consideran destinado solo a los miembros de la misma etnia.

Como respuesta a la invasión a la que son sometidos y comprometidos con su cultura día a día, el pueblo Wixarika ha realizado diversas acciones entre las que se destacan la conformación en abril del 2010 del Consejo Regional Wixarika por la Defensa de Wirikuta, así mismo, el 7 de febrero del 2012 y la Declaración de Wirikuta (Emergencia Mx, 2012), en donde los Wixarikas pacíficamente defienden lo que consideran su esencia, ofrecen y solicitan respeto a la diversidad cultural, reiteran que el conocimiento ancestral que poseen es un legado para la humanidad, expresan nuevamente que el daño que causan en su entorno propicia que entristezcan sus corazones y muera su ser, recuerdan que el camino espiritual es del color del maíz, del venado y del hikuri, solicitan mayor sensibilidad a su causa mediante consulta previa, informada y concensada de los pueblos involucrados, otorgan reconocimiento y gratitud a quienes se han solidarizado con su causa y recuerdan al mundo, que el pueblo wixárica está unido en pro de su herencia cultural.

En esta nueva etapa, en la que el núcleo de su cosmovisón se está viendo seriamente amenazado por intereses de una magnitud a la que el pueblo wixárika nunca se había enfrentado antes, una vez más están utilizando sus nuevas formas de arte para mantener el diálogo y buscar el apoyo de gente ajena a sus costumbres, dispuesta a unirse a su causa. Es un reto mayor porque ahora su espiritualidad, protegida siempre de las miradas externas por el arte mismo, es la que está puesta en el centro del mensaje que se quiere comunicar: que Wirikuta es el corazón de su religiosidad como El Vaticano lo es del catolicismo. Es un mensaje complejo de explicar sin exponer su esencia cultural a los indeseados debates de la opinión pública. Pero sin duda, es una causa que los wixaritari puede expresar a través de su arte. Conozcamos la causa, salvemos a Wirikuta, corazón sagrado de México. 


\section{Referencias bibliográficas}

68 voces (2016). "Huichol, El primer amanecer", en Seseinta y ocho voces, sesenta y ocho corazones. Recuperado de: https://68voces.mx/huichol-el-primer-amanecer

Amazon (2019). NOVICA decorativos huichol Beaded Máscara de papel maché, multicolor, 'jicuri Dance'. Amazon México. Recuperado de: https://www.amazon.com.mx/NOVICAdecorativos-huichol-M\%C3\%A1scara-multicolor/dp/B0057Y0MVG/ref=sr_1_4?_mk_ es_MX=\%C3\%85M $\% \mathrm{C} 3 \% 85 \% \mathrm{C} 5 \% \mathrm{BD} \% \mathrm{C} 3 \% 95 \% \mathrm{C} 3 \% 91 \&$ keywords=novica + huicho 1\&qid $=1566154914 \& \mathrm{~s}=$ gateway\&sr $=8-4$

Anguiano, M. (2016). "El arte huichol de México y sus simbolos sagrados". Conferencia Magistral DEAS-INAH. México. Recuperado de 2019 de: https://www.academia. edu/28516885/El_arte_huichol_y_sus_simbolos_sagrados_Conferencia_Magistral_ DEAS_2016

Artes de México (2005, julio). “Arte huichol”. Revista-libro Artes de México. №. 75, México: Artes de México y del Mundo - Consejo Nacional para la Cultura y las Artes.

Chapela, L. M. (2006). Wixárika: Un pueblo en comunicación. México, D.F., México: Secretaría de Educación Pública, Coordinación General de Educación Intercultural y Bilingüe. Recuperado de 2019 de: https://bpo.sep.gob.mx/\#/recurso/4500/document/1

Comisión Nacional para el Desarrollo de los Pueblos Indígenas (2010). Informe final de Consulta sobre Lugares Sagrados del Pueblo Wixarika. $2^{\text {a }}$ ed, México.

De Diputados, C. (2012). Constitución política de los estados unidos mexicanos. México: Cámara de Diputados.

Emergencia Mx, (2012). Declaración de Wirikuta_7 de febrero 2012. Recuperado de: https:// www.youtube.com/watch?v=p0WiYCMdY6o

Ibarra, R. y Armenta, J.C. (2005, 18 de abril). "La cosmogonía huichol en un mural”. Gaceta Universitaria, p. 24. Recuperado de: http://www.gaceta.udg.mx/Hemeroteca/paginas 1386/386-24.pdf

INAH. (s.f.). El cuadro. La tabla huichola: Arte Nierika. Caminos de luz. Universos huicholes. Instituto Nacional de Antropología e Historia. [en línea]. Recuperado de: https:// universoshuicholes.inah.gob.mx/cuadro.html

Le Mûr, R. (2015). "La evolución del arte huichol junto al turismo. Entre apreciación y apropiación cultural”. Desacatos, No. 49, septiembre-diciembre.

López, A. (2016). “Sobre la cosmovisión en López, A. La cosmovisión e la tradición mesoamericana, primera parte”. Revista Arqueología Mexicana, edición especial 89. México : Editorial Raíces - Instituto Nacional de Antropología e Historia.

Lumholtz, C. (1986): El arte simbólico y decorativo de los huicholes. México, D.F. Instituto Nacional Indigenista.

Mata, R. (1972). "Vida y arte de los huicholes". Revista Artes de México, No 161, Segunda parte: El Arte. México: Artes de México.

Negrín, D. (2015). "El indio que todos quieren: el consumo de lo 'huichol' tras la batalla por Wirikuta”. En: Sociedad y Ambiente, año 3, vol. 1, núm. 8.

Neurath, J. (2003). Pueblos indígenas del México Contemporáneo. Huicholes. Comisión Nacional para el Desarrollo de los Pueblos Indígenas. México, D.F. Recuperado de: https:// www.gob.mx/cms/uploads/attachment/file/11223/huicholes.pdf 
Neurath, J. (2013). La vida de las imágenes. Arte huichol. México : Artes de México - Consejo Nacional para la Cultura y las Artes.

Pacheco, G. y Iturrioz, J. L. (2003). José Benitez y el arte huichol. La semilla del mundo. México: Consejo Nacional para la cultura y las Artes.

San Luis Potosí (1995). Constitución Política del Estado Libre y Soberano de San Luis Potosí. México, D.F: Fondo de Cultura Económica.

Semarnat (2010). "Norma Oficial Mexicana NOM-059-SEMARNAT-2010, Protección ambiental-Especies nativas de México de flora y fauna silvestres-Categorías de riesgo y especificaciones para su inclusión, exclusión o cambio-Lista de especies en riesgo". Diario oficial de la federación, 110.

Sistema de Información Cultural. SIC México. La peregrinación a Wirikuta. Recuperado de: https://sic.cultura.gob.mx/ficha.php?table=frpintangible\&table_id=262

Téllez Lozano, V. M. (2014): "Acercamiento al estudio de los sistemas de cargos entre las comunidades huicholas de Jalisco y Nayarit”. Diálogo andino, (43), 17-40

Torres Barreto, A., y Castrejón García, G. E. (2016): “La lucha wixarika por wirikuta y su territorialidad. La responsabilidad patrimonial del estado como instrumento jurídico de defensa. Multidisciplina”Año 8, número 23. (Enero -abril, 2016).

\begin{abstract}
The Wixárica or Huichol people is one of the oldest indigenous communities in Mexico, and they are popularly associated with various myths, such as considering them the last guardians of authentic pre-Hispanic traditions or believing them to be a people of shamans due to the ritual use they make of them. a hallucinogenic mushroom they call hikuri. Based on the experiences resulting from the use of this hallucinogen and its own cosmogony, the Wixárika have developed a psychedelic aesthetic that manifests itself in various artistic expressions that are highly appreciated for their technique, complexity, beauty and mysticism that they seem to keep. This art has allowed them to become visible in a nation that does not tend to attend to their native peoples and has also been the "signature" they have presented in their struggles against the dispossession of their lands and Wirikuta, an extensive territory considered one of the sites most sacred to this culture, and that is at risk of disappearing under mining interests. The purpose of this article is to describe this particular style of wixárika art and the value it has had as a sign of identity in the defense of Wirikuta and its entire culture.
\end{abstract}

Keywords: Huicholes - Wirikuta - Wixárika art - Mexican Indians - Huichol art.

Resumo: Os Wixarica ou Huichol pessoas é uma das mais antigas comunidades indígenas no México, e estão associados normalmente com vários mitos, como consideram os últimos guardiões da autênticas tradições pré-hispânicas ou acreditar neles uma cidade de xamãs por causa do uso ritual feito de um cogumelo alucinógeno que eles chamam hikuri. A partir das experiências resultantes da utilização deste alucinógeno e sua própria cosmogonia, os wixárika desenvolveram uma estética psicodélica que se manifesta de várias 
formas de arte apreciados pela sua técnica, sua complexidade, sua beleza e misticismo que parecem manter. Esta arte lhes permitiu tornar-se visível em uma nação que não costuma atender a suas cidades originais e também tem sido "assinatura" que ocorreram em suas lutas contra a desapropriação de suas terras e Wirikuta, um vasto território considerado um dos locais mais sagrado para essa cultura, e é em risco de desaparecer sob interesses de mineração. O objetivo deste artigo é descrever este estilo particular de arte Huichol eo valor tem sido como um sinal de identidade na defesa de Wirikuta e toda sua cultura.

Palavras chave: Huicholes - Wirikuta - Arte wixárika - Indios mexicanos - Arte huichol.

[Las traducciones de los abstracts fueron supervisadas por el autor de cada artículo] 